\title{
Produção de laranja com plantas de cobertura permanente na entrelinha
}

\author{
Jonez Fidalski(1), Celso Jamil Marur(2), Pedro Antonio Martins Auler ${ }^{(1)}$ e Cássio Antonio Tormena ${ }^{(3)}$
}

\begin{abstract}
(1)Instituto Agronômico do Paraná (lapar), Estação Experimental de Paranavaí, Caixa Postal 564, CEP $87701-970$ Paranavaí, PR. E-mail: fidalski@iapar.br, aulerpe@iapar.br (2)Iapar, Caixa Postal 481, CEP 86001-970 Londrina, PR. E-mail: cjmarur@iapar.br (3)Universidade Estadual de Maringá, Dep. de Agronomia, Av. Colombo, no 5.790, CEP 87020-900 Maringá, PR. E-mail: catormena@uem.br
\end{abstract}

\begin{abstract}
Resumo - O objetivo deste trabalho foi avaliar as relações hídricas, os parâmetros fisiológicos e a produção de frutos da laranjeira 'Pêra' enxertada sobre o limoeiro 'Cravo', assim como a umidade do solo, em diferentes plantas de cobertura permanente na entrelinha. O experimento de campo foi implantado em 1993, em Argissolo Vermelho distrófico latossólico, no Município de Alto Paraná, noroeste do Paraná. Foram avaliados três tratamentos: gramínea (Paspalum notatum), leguminosa (Arachis pintoi) e testemunha, que consistiu na dessecação da vegetação espontânea com herbicida. O delineamento experimental foi de blocos ao acaso com três repetições. De 1999 a 2003, realizaram-se avaliações da taxa de fotossíntese, condutância estomática e potencial da água das plantas, produção de frutos e umidade do solo. A manutenção da leguminosa nas entrelinhas do pomar acentua o estresse hídrico nas laranjeiras. O manejo da gramínea nas entrelinhas assegura melhores relações hídricas e metabólicas às laranjeiras. A produção de frutos da laranjeira 'Pêra' não é comprometida pelo manejo das plantas de cobertura na entrelinha do pomar.
\end{abstract}

Termos para indexação: Citrus, fotossíntese, condutância estomática, potencial da água na folha.

\section{Orange yield in orchard floor vegetation management}

\begin{abstract}
The objective of this work was to evaluate water status, physiological parameters and fruit yield of the Pear orange on Rangpur lime rootstock, as well as soil water content in different orchard floor vegetation management. Field experiment was set up in 1993, at Alto Paraná, northwest of the state of Paraná, Brazil. The soil is a Typic Paleudults. Three treatments were evaluated: bahiagrass (Paspalum notatum), legume (Arachis pintoi), and spontaneous vegetation plus herbicide. The experimental design was in random blocks with three replicates. From 1999 to 2003, the following measurements were made: photosynthesis rates, stomatal conductance, leaf water potential, fruit yield and soil water content. Legume keeping in the interrows causes higher stress to orange plants. Bahiagrass assures better water and metabolic relations to Pear orange tree. Fruit yield orange is not influenced by orchard floor vegetation management.
\end{abstract}

Index terms: Citrus, photosynthetic rates, stomatal conductance, leaf water potential.

\section{Introdução}

No Brasil, o manejo do solo de pomares de laranjeira evoluiu entre as décadas de 50 e 90, com estudos demonstrando a eficiência da cobertura morta (“mulching”), vegetação permanente com gramíneas ou leguminosas, adubação verde, gradagem, subsolagem e controle da vegetação com herbicida nas entrelinhas (Neves et al., 1998; Neves \& Dechen, 2001; Auler et al., 2004; Souza et al., 2004).

Paralelamente, o cenário mundial de manejo dos pomares tem restringido o revolvimento mecânico e a uti- lização de herbicidas para o controle da vegetação nas linhas das plantas, sendo recomendada a manutenção das entrelinhas com gramíneas, para assegurar melhor qualidade do solo (Butler, 1986; Santinoni \& Silva, 1995; Lipecki \& Berbeć, 1997; Draghi et al., 2005). Porém, a manutenção da vegetação nas entrelinhas dos pomares poderia promover a competição por água e nutrientes, e comprometer a produção de frutos das plantas perenes, principalmente em solos com menor retenção de água (Lipecki \& Berbeć, 1997; Neves \& Dechen, 2001).

O comportamento fisiológico de laranjeira tem mostrado redução na taxa de assimilação de $\mathrm{CO}_{2}$ sob con- 
dições de deficiência hídrica (Chartzoulakis et al., 1999; Medina et al., 1999), com o fechamento dos estômatos, a partir do potencial da água nas folhas de -2,0 MPa (Machado et al., 1999; Medina et al., 1999).

Em condição climática brasileira, o estresse hídrico é comum durante o inverno e beneficia o florescimento de laranjeiras, mas seu prolongamento pode comprometer o desenvolvimento e a produção de frutos (Syvertsen, 1999). São desconhecidas as relações hídricas e fisiológicas de laranjeiras nos estádios fenológicos de pré e pós-florescimento, bem como a produção de frutos em condições de manejo da vegetação permanente nas entrelinhas dos pomares.

O objetivo deste trabalho foi avaliar as relações hídricas, os parâmetros fisiológicos e a produção de frutos de laranjeira 'Pêra', enxertadas sobre o limoeiro 'Cravo', assim como a umidade do solo, em três plantas de cobertura permanente nas entrelinhas do pomar.

\section{Material e Métodos}

O estudo foi realizado em área experimental localizada na Fazenda São Judas Tadeu, no Município de Alto Paraná, noroeste do Paraná (2305'S, 52²6'W e altitude de $480 \mathrm{~m}$ ). O clima da região é subtropical (Cfa), sem estação seca definida, caracterizado por maiores precipitações entre outubro e março, com precipitações mensais de 100-200 mm, e menores precipitações entre abril e setembro, com $25-125$ mm, e precipitações anuais de $1.400 \mathrm{~mm}$ (Iapar, 2000). O solo foi identificado como Argissolo Vermelho distrófico latossólico, textura areia/franco siltoso A moderado, relevo suave ondulado. Os teores de argila e a espessura dos horizontes do solo foram: A (80 g kg-1 e 0-0,25 m), Bt (180 $\mathrm{g} \mathrm{kg}^{-1}$ e 0,26-0,55 m) e Bw (210 $\mathrm{g} \mathrm{kg}^{-1}$ e 0,56-2,00 m).

O experimento de laranjeira 'Pêra' [Citrus sinensis (L.) Osbeck], enxertada sobre o limoeiro 'Cravo' (Citrus limonia Osbeck), foi implantado em 1993, utilizando o preparo convencional do solo (aração e grade niveladora), em área anteriormente ocupada por pastagem de Brachiaria humidicola. O delineamento experimental utilizado foi de blocos ao acaso, com três repetições e três tratamentos de manejo nas entrelinhas. Cada parcela experimental apresentou 15 plantas, com três linhas no espaçamento de $7 \mathrm{~m}$, contendo cinco plantas, dentro de cada linha, espaçadas em $4 \mathrm{~m}$. As avaliações hídricas - umidade do solo -, fisiológicas - taxa de fotossíntese, condutância estomática e potencial da água das plantas - e fitotécnicas - produção de frutos - foram realizadas na planta central de cada parcela experimental.

Os tratamentos utilizados no manejo na entrelinha das laranjeiras foram: gramínea - cobertura permanente com grama mato grosso ou batatais (Paspalum notatum), com roçada mecânica; leguminosa - cobertura permanente com amendoim forrageiro (Arachis pintoi), sem roçada mecânica; e testemunha - controle da vegetação espontânea com herbicida pós-emergente (glifosato), aplicado com o propósito de manter baixa cobertura do solo, tendo sido utilizado em 1998, 1999, 2000, 2001 e 2002, respectivamente, três, duas, uma e nenhuma aplicação de herbicida nos últimos dois anos, nos quais foram utilizadas roçadas mecânicas. A vegetação da linha de plantio foi controlada por meio de capina e herbicida (glifosato).

Na caracterização físico-hídrica do solo, foi realizada abertura de uma trincheira de $2 \mathrm{~m}$ de profundidade, na qual foi efetuada a identificação morfológica dos horizontes $\mathrm{A}, \mathrm{B}_{\mathrm{t}}$ e $\mathrm{B}_{\mathrm{w}}$. Foram coletadas amostras de solo indeformadas em anéis metálicos de $100 \mathrm{~cm}^{3}$; em seguida, as amostras foram saturadas em bandejas, mantendo-se uma lâmina de água até dois terços da altura dos anéis, e submetidos aos potenciais mátricos: $-0,001,-0,002,-0,004,-0,006$ e -0,008 MPa, em uma mesa de tensão, e $-0,01,-0,03,-0,05,-0,07,-0,1-0,4$ e -1,5 MPa, em câmaras de pressão (Dane \& Topp, 2002). Depois de atingir equilíbrio, as amostras foram secadas em estufa a $110^{\circ} \mathrm{C}$ por 24 horas, e pesadas para determinação da umidade e densidade do solo (Dane \& Topp, 2002). A curva de retenção de água no solo foi ajustada pelo modelo matemático proposto por Van Genuchten (1980), equação $\theta \mathrm{g}=\theta \mathrm{r}+\left\{(\theta \mathrm{s}-\theta \mathrm{r}) /\left[(1+\alpha \psi)^{\mathrm{n}}\right]^{(1-1 / \mathrm{n})}\right\}$, em que $\theta g$ é a umidade gravimétrica $\left(\mathrm{kg} \mathrm{kg}^{-1}\right) ; \psi$ é o módulo do potencial mátrico (hPa); $\theta$ r é o conteúdo de água residual $\left(\mathrm{m}^{3} \mathrm{~m}^{-3}\right)$; $\theta$ s é o conteúdo de água na saturação $\left(\mathrm{m}^{3} \mathrm{~m}^{-3}\right)$; e $\alpha$ e n são coeficientes empíricos do modelo (Figura 1).

As amostragens para determinação da umidade gravimétrica do solo e as avaliações fisiológicas das laranjeiras realizaram-se em dois períodos. O primeiro período consistiu de quatro avaliações (20/8, 10/9 e 24/11/1999 e 5/4/2000), e o segundo período, de cinco avaliações (18/4, 23/5, 18/7, 23/8 e 11/10/2002). Estes dois períodos apresentaram em comum a fase de pré e pós-florescimento (agosto-outubro), constituindose no estádio fenológico e hídrico mais crítico para o cultivo de citros na região noroeste do Paraná (Calheiros et al., 1992). As precipitações mensais do período experimental foram obtidas na Estação Meteorológica do Iapar, Paranavaí (Figura 2). 
A determinação da umidade gravimétrica do solo foi realizada mediante coleta de amostras de solo por meio de um trado do tipo sonda nas camadas de $0-0,1$, $0,1-0,2,0,2-0,4,0,4-0,6,0,6-0,8$ e $0,8-1,0$ m de profundidade, nas entrelinhas do pomar de laranjeira, nas avaliações realizadas no primeiro período, e nas camadas de $0-0,1,0,1-0,2,0,2-0,3$ e $0,3-0,4 \mathrm{~m}$ de profundidade, nas entrelinhas e sob a projeção da copa das plantas, nas avaliações realizadas no segundo período. Essas amostras foram secadas em estufa a $110^{\circ} \mathrm{C}$ por 24 horas, para obter a massa de água e de sólidos do solo. Nas projeções das copas das laranjeiras, havia uniformidade quanto à ausência de cobertura vegetal em todos os tratamentos, resultante do controle da vegetação com herbicida, ao passo que, nas entrelinhas, havia diferenças da cobertura vegetal do solo promovida por diferentes tratamentos.

Em cada uma das nove avaliações do primeiro e segundo períodos, foram realizadas de três a cinco leituras da taxa de fotossíntese $\left(\mu \mathrm{mol} \mathrm{CO} \mathrm{CO}_{2} \mathrm{~m}^{-2} \mathrm{~s}^{-1}\right)$, da condutância estomática ( $m o l \mathrm{H}_{2} \mathrm{O} \mathrm{m}^{-2} \mathrm{~s}^{-1}$ ) e da temperatura $\left({ }^{\circ} \mathrm{C}\right)$, no intervalo compreendido entre $8 \mathrm{e} 16 \mathrm{~h} 30$. As leituras foram obtidas por meio de aparelho portátil de medida de fotossíntese (LI-6200, LICOR Inc.), utilizando câmara com volume de $1 \mathrm{~L}$; em 18/4/2002, em virtude de problemas de configuração do equipamento, as leituras não foram realizadas.

As medições foram efetuadas na planta central de cada parcela experimental, em duas folhas próximas, totalmente desenvolvidas, localizadas na porção mediana da copa das plantas. A fim de se evitar desuniformidade nas leituras, em relação à incidência dos raios solares, as folhas

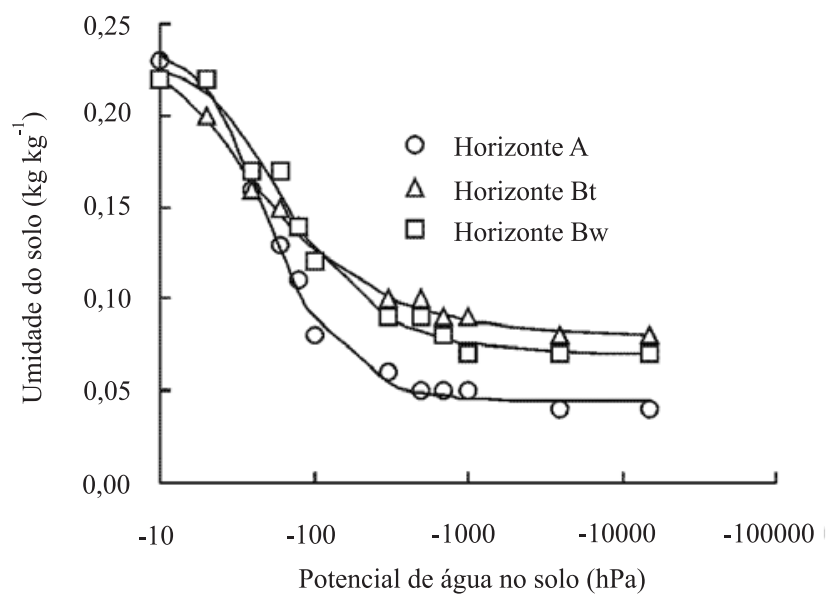

Figura 1. Curvas de retenção de água do solo para cada um dos três horizontes do Argissolo Vermelho distrófico latossólico, determinadas em novembro de 2003. amostradas foram aquelas em que os raios incidiam diretamente, mudando-se, portanto, a posição das amostragens nas plantas, no decorrer das avaliações. Procedeu-se também à determinação do potencial da água (MPa) em folhas próximas às descritas anteriormente, utilizando câmara de pressão (PMS-1000 SoilMoisture) do tipo Scholander (Scholander et al., 1965).

As colheitas dos frutos de laranjeira foram realizadas em 14/8/2000 (1 a florada em agosto de 1999), 29/12/2000 (2 a florada em dezembro de 1999), 14/8/2001 (1a florada de 2000), 14/12/2001 (2a florada de 2000), 4/7/2002 e 17/7/2003, em cada uma das plantas centrais da parcela experimental.

Os dados originais das determinações de umidade gravimétrica do solo, avaliações fisiológicas - taxa de fotossíntese, condutância estomática e potencial da água das plantas - e a produção dos frutos foram analisados por meio do modelo matemático de blocos ao acaso, determinando-se a análise de variância e o teste de comparação de médias, individualmente, para cada variável resposta e a cada uma das avaliações, camadas de solo (umidade gravimétrica do solo) e horário (avaliações fisiológicas). Essas análises estatísticas e os coeficientes de regressão dos modelos da curva de retenção (procedimento NLIN) foram obtidos com o SAS (SAS Institute, 2001).

\section{Resultados e Discussão}

A sazonalidade da taxa de fotossíntese, da condutância estomática e do potencial da água das laranjeiras foi decrescente de abril a novembro (Figura 3). À exceção do potencial da água nas folhas, a amplitude da taxa de fotossíntese e da condutância estomática contempla valores mínimos e máximos (Medina et al., 1999; Machado et al., 1999, 2002).

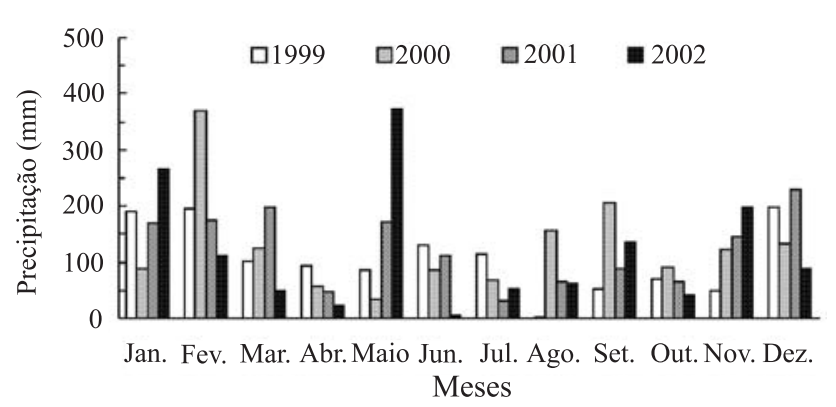

Figura 2. Precipitações mensais durante o período experimental (1999 a 2002). 
A influência dos tratamentos na taxa de fotossíntese das laranjeiras foi constatada em agosto de 1999 e 2002 (Tabela 1). Observaram-se, no tratamento gramínea, as
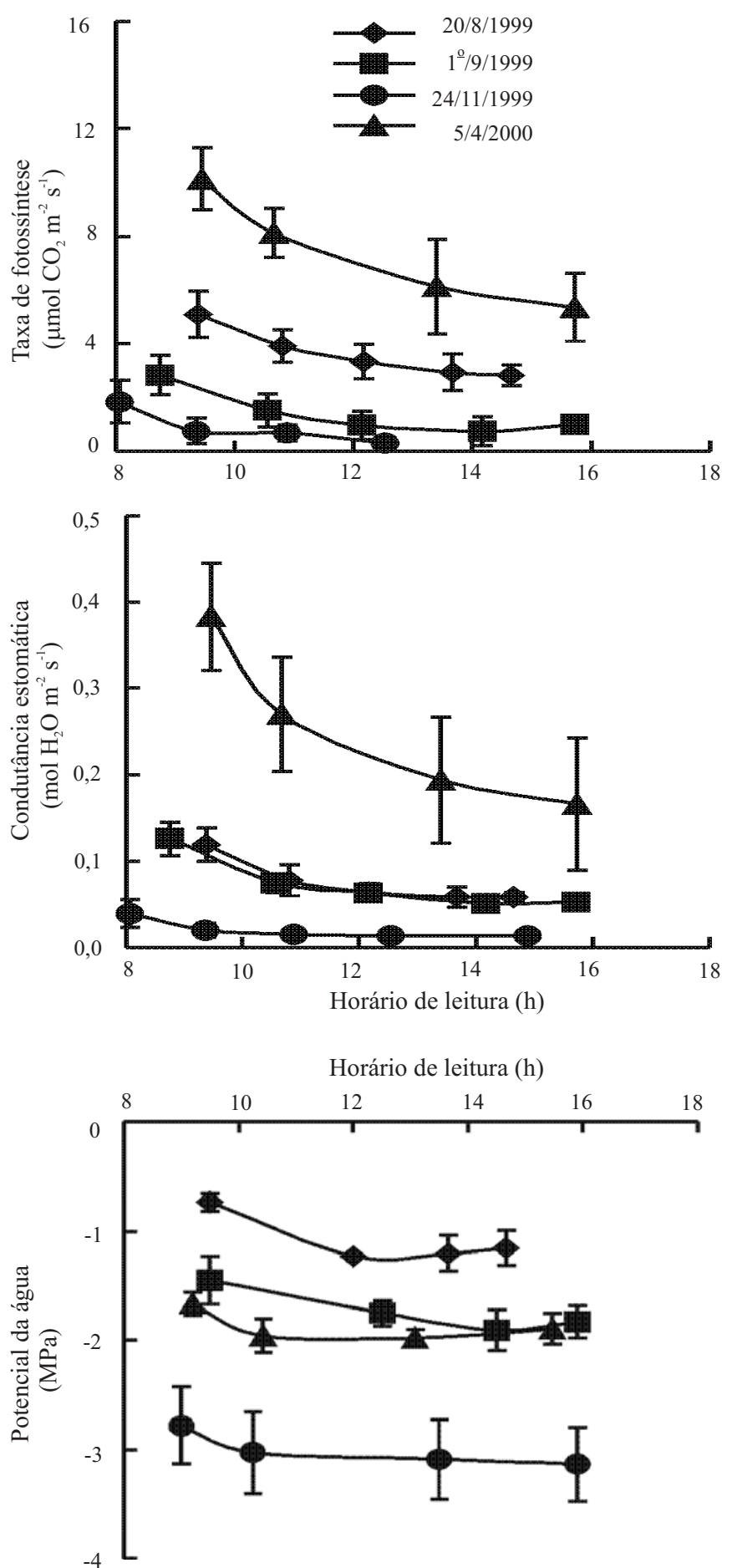

menores reduções na taxa de fotossíntese $(\mathrm{p}<0,05)$, respectivamente, $4,48 \mu \mathrm{mol} \mathrm{CO} \mathrm{m}^{-2} \mathrm{~s}^{-1}$, em 20/8/1999 e 4,34 $\mu \mathrm{mol} \mathrm{CO} \mathrm{m}^{-2} \mathrm{~s}^{-1}$, em 24/8/2002 (Tabela 1).
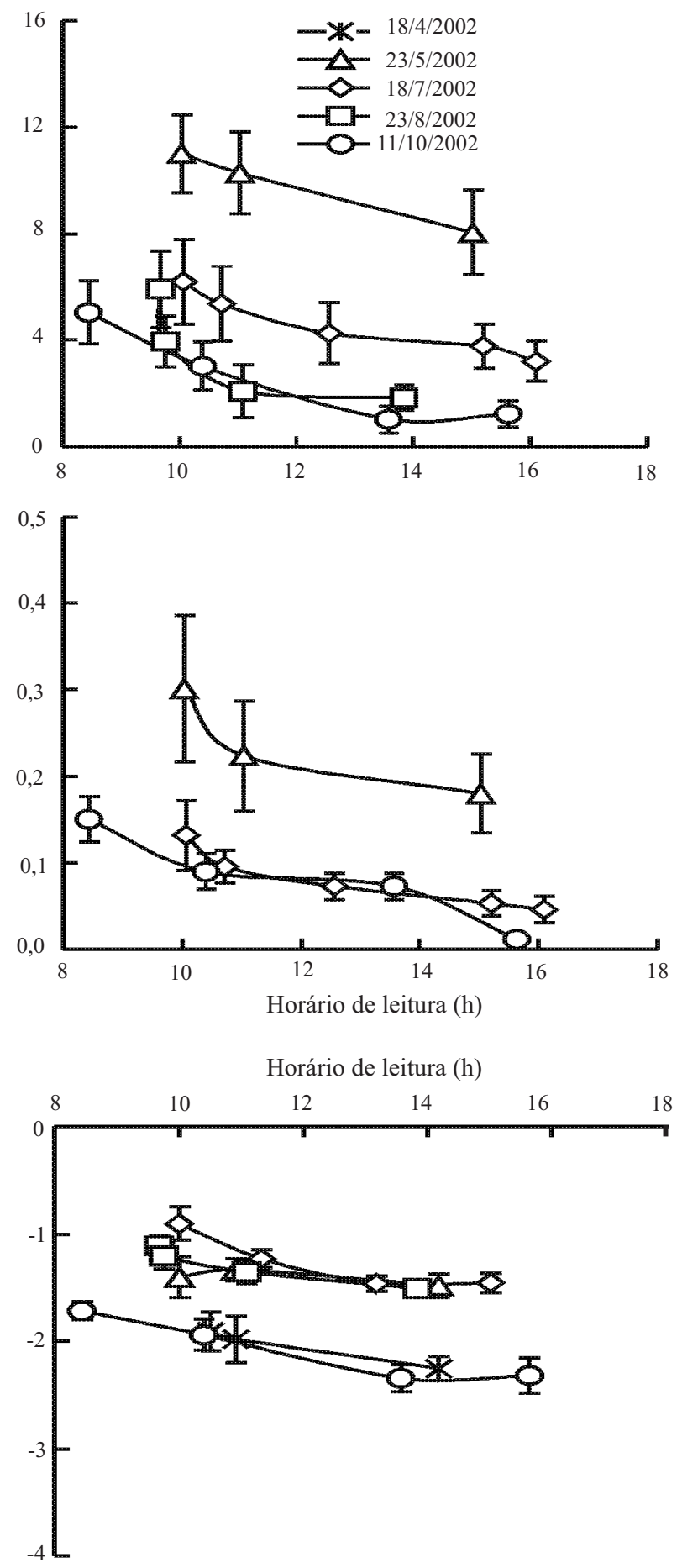

Figura 3. Taxa de fotossíntese, condutância estomática e potencial da água das laranjeiras 'Pêra', em nove avaliações, durante os dois períodos de avaliação (1999/2000 e 2002). As barras verticais indicam o desvio-padrão dos dados independentes dos tratamentos (gramínea, leguminosa e testemunha). 
Os tratamentos leguminosa e testemunha apresentaram comportamento distinto, nas duas avaliações. Esses resultados caracterizam a influência do manejo de solo na indução do florescimento das laranjeiras, sendo o deficit hídrico um fator importante, conforme Syvertsen (1999).

Houve menores precipitações em agosto e setembro de 1999, que desencadearam e estabeleceram um período de estiagem que se prolongou até novembro de 1999 (Figura 2), condição atípica, quando comparada com os dados climáticos da região (Iapar, 2000). Essas menores precipitações refletiram na redução da taxa de fotossíntese das laranjeiras em 20/8/1999, $1 / 9 / 1999$ e $24 / 11 / 1999$, as quais mantiveram a mesma dependência dos tratamentos (Tabela 1). Esta constatação se evidencia pela comparação com as maiores taxas de fotossíntese em 5/4/2000 e 23/5/2002. Esses fenômenos estariam relacionados às variações do conteúdo de água no solo, controlados via comunicação raiz-parte aérea (Chartzoulakis et al., 1999; Medina et al., 1999).
Observou-se maior umidade do solo nas entrelinhas do pomar com gramínea, confirmando a maior taxa de fotossíntese neste tratamento (Figura 4 e Tabela 1). Com a estiagem em 1999, a umidade do solo se diferenciou entre os tratamentos nas profundidades de 0,5 , 0,7 e $0,9 \mathrm{~m}$ nas entrelinhas, correspondendo aos horizontes $\mathrm{Bt}$ e $\mathrm{Bw}$ com maiores teores de argila (180 e $210 \mathrm{~g} \mathrm{~kg}^{-1}$ ). Temporalmente, não foi constatada a redução da umidade do solo no tratamento com gramínea; ao contrário, os tratamentos leguminosa e testemunha apresentaram menor umidade do solo (Figura 4), atribuída ao sistema radicular e à taxa de evapotranspiração das espécies nas entrelinhas do pomar (Butler, 1986; Espindola et al., 1998; Neves et al., 1998; Perin et al., 2000).

Com o prolongamento da estiagem de 1999, em 1ㅇ9/1999, as laranjeiras apresentavam redução da taxa de fotossíntese, sem o comprometimento da condutância estomática, mantida pelos potenciais da água máximo de -1,9 MPa (Figura 3), próximo ao valor considerado limite, de $-2 \mathrm{MPa}$, para a manutenção dos estômatos

Tabela 1. Taxa de fotossíntese ( $\left.\mu \mathrm{mol} \mathrm{CO}_{2} \mathrm{~m}^{-2} \mathrm{~s}^{-1}\right)$, condutância estomática $\left(\mathrm{mol} \mathrm{H}_{2} \mathrm{O} \mathrm{m}^{-2} \mathrm{~s}^{-1}\right)$ e potencial da água (MPa) de laranjeira 'Pêra', nos tratamentos que apresentaram diferenças significativas entre as médias dessas variáveis, nas datas e horários (h) determinados ${ }^{(1)}$.

\begin{tabular}{|c|c|c|c|c|c|}
\hline Tratamento & Data & Horário & $\begin{array}{c}\text { Taxa } \\
\text { de fotossíntese }\end{array}$ & $\begin{array}{c}\text { Condutância } \\
\text { estomática }\end{array}$ & $\begin{array}{c}\text { Potencial } \\
\text { da água }\end{array}$ \\
\hline Gramínea & $20 / 8 / 1999$ & $10 \mathrm{~h} 48$ & $4,48 \mathrm{a}$ & $0,0870 \mathrm{a}$ & - \\
\hline Leguminosa & & & $3,45 b$ & $0,0768 \mathrm{a}$ & - \\
\hline Testemunha & & & $3,81 \mathrm{ab}$ & $0,0709 \mathrm{a}$ & - \\
\hline Gramínea & $1^{0} / 9 / 1999$ & $8 \mathrm{~h} 45$ & $3,46 \mathrm{a}$ & $0,1336 a$ & $-1,40 \mathrm{a}$ \\
\hline Leguminosa & & & $2,21 b$ & $0,1185 \mathrm{a}$ & $-1,52 \mathrm{a}$ \\
\hline Testemunha & & & $2,80 \mathrm{ab}$ & $0,1267 \mathrm{a}$ & $-1,43 a$ \\
\hline Gramínea & $24 / 11 / 1999$ & $8 \mathrm{~h} 10$ & $1,80 \mathrm{a}$ & $0,0432 a$ & $-2,70 \mathrm{ab}$ \\
\hline Leguminosa & & & $1,42 \mathrm{a}$ & $0,0322 a$ & $-3,18 \mathrm{a}$ \\
\hline Testemunha & & & $2,28 \mathrm{a}$ & $0,0446 \mathrm{a}$ & $-2,47 b$ \\
\hline Gramínea & $24 / 11 / 1999$ & $9 \mathrm{~h} 21$ & $0,64 a$ & $0,0210 \mathrm{a}$ & $-2,89 b$ \\
\hline Leguminosa & & & $0,35 \mathrm{a}$ & $0,0165 \mathrm{a}$ & $-3,48 \mathrm{a}$ \\
\hline Testemunha & & & $1,26 \mathrm{a}$ & $0,0234 \mathrm{a}$ & $-2,72 b$ \\
\hline Gramínea & $24 / 11 / 1999$ & $10 \mathrm{~h} 53$ & $0,84 a$ & $0,0143 \mathrm{ab}$ & $-2,86 b$ \\
\hline Leguminosa & & & $0,36 \mathrm{~b}$ & $0,0120 b$ & $-3,55 a$ \\
\hline Testemunha & & & $0,85 \mathrm{a}$ & $0,0205 \mathrm{a}$ & $-2,87 b$ \\
\hline Gramínea & $24 / 11 / 1999$ & $12 \mathrm{~h} 32$ & $0,31 \mathrm{a}$ & $0,0159 a$ & $-3,01 b$ \\
\hline Leguminosa & & & $0,38 \mathrm{a}$ & $0,0100 \mathrm{a}$ & $-3,55 \mathrm{a}$ \\
\hline Testemunha & & & $0,24 \mathrm{a}$ & $0,0172 \mathrm{a}$ & $-2,86 b$ \\
\hline Gramínea & $23 / 8 / 2002$ & $9 \mathrm{~h} 45$ & $4,34 a$ & - & $-1,27 a$ \\
\hline Leguminosa & & & $4,07 \mathrm{ab}$ & - & $-1,18 \mathrm{a}$ \\
\hline Testemunha & & & $3,45 b$ & - & $-1,17 \mathrm{a}$ \\
\hline Gramínea & $11 / 10 / 2002$ & $10 \mathrm{~h} 21$ & $3,49 a$ & $0,0828 \mathrm{a}$ & $-1,98 \mathrm{a}$ \\
\hline Leguminosa & & & $2,87 \mathrm{a}$ & $0,0979 a$ & $-1,83 b$ \\
\hline Testemunha & & & $2,75 a$ & $0,0900 \mathrm{a}$ & $-2,02 \mathrm{a}$ \\
\hline Gramínea & $11 / 10 / 2002$ & $15 \mathrm{~h} 32$ & $1,34 \mathrm{a}$ & $0,0134 a$ & $-2,36 a$ \\
\hline Leguminosa & & & $1,49 a$ & $0,0114 \mathrm{ab}$ & $-2,25 a$ \\
\hline Testemunha & & & $0,89 a$ & $0,0100 \mathrm{~b}$ & $-2,35 a$ \\
\hline
\end{tabular}

${ }^{(1)}$ Médias seguidas pela mesma letra, na coluna, para a mesma data e horário, não diferem entre si pelo teste Tukey a 5\% de probabilidade. 
abertos para as trocas gasosas (Chartzoulakis et al., 1999; Machado et al., 1999; Medina et al., 1999; Syvertsen, 1999).
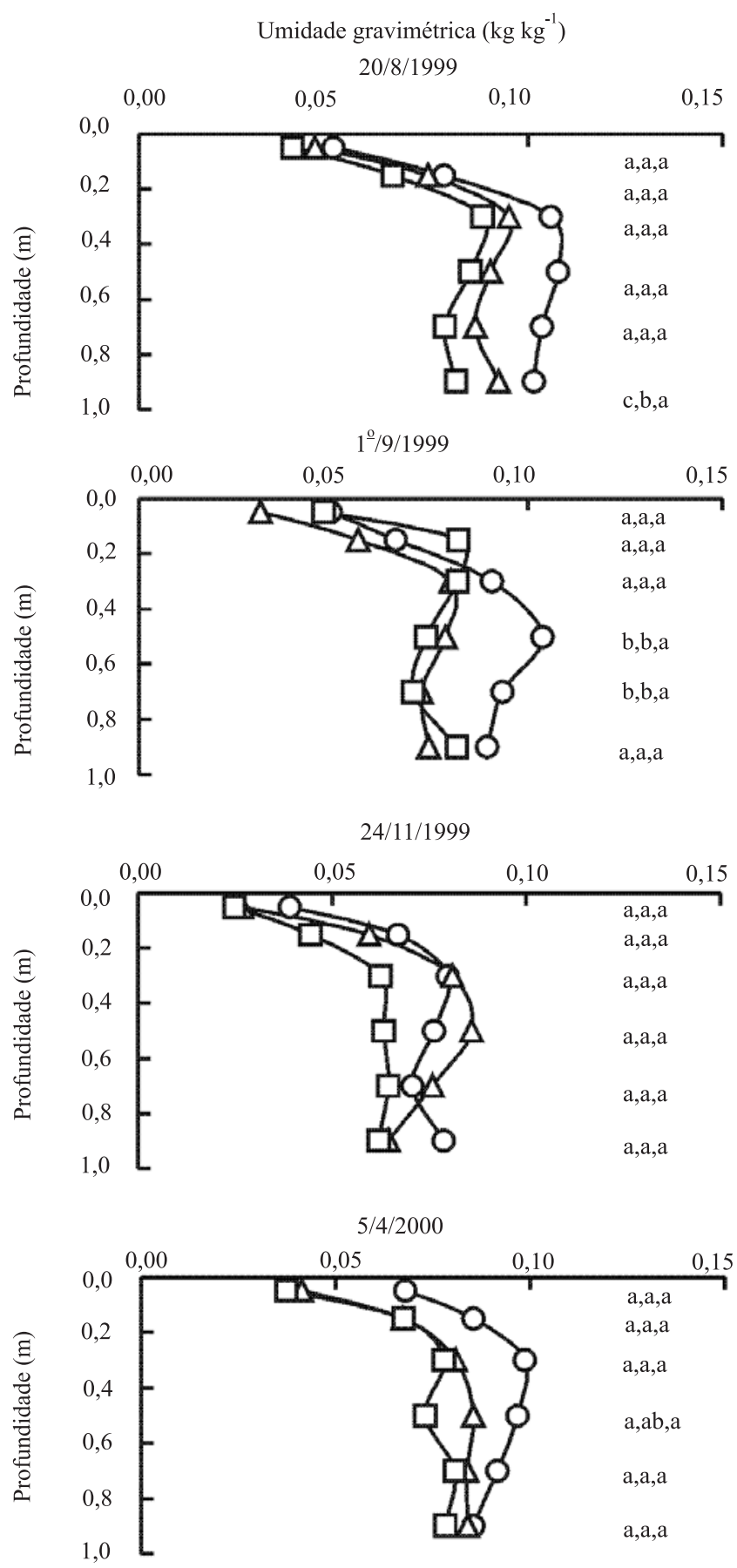

Figura 4. Umidade gravimétrica do solo na entrelinha do pomar de laranjeira 'Pêra' em 1999/2000, nos tratamentos gramínea $(\bigcirc)$, leguminosa $(\square)$ e testemunha $(\triangle)$. Médias seguidas da mesma letra, dentro da mesma camada de solo, não diferem entre si pelo teste Tukey a 5\% de probabilidade.
A redução progressiva da umidade do solo (Figura 4) culminou em 24/11/1999, com o estresse hídrico das laranjeiras, caracterizado pela presença de folhas enroladas pela manhã no tratamento leguminosa e, a partir do meio-dia, nos tratamentos gramínea e testemunha. Neste momento, foram constatados os menores valores de taxa de fotossíntese $\left(\leq 0,85 \mu \mathrm{mol} \mathrm{CO} \mathrm{m}^{-2} \mathrm{~s}^{-1}\right)$; potenciais da água $(\leq-2,47 \mathrm{MPa})$ e condutância estomática $\left(\leq 0,02 \mathrm{~mol} \mathrm{H}_{2} \mathrm{O} \mathrm{m}^{-2} \mathrm{~s}^{-1}\right)$ (Figura 3 e Tabela 1 ), que caracterizaram a baixíssima condutância estomática, com os estômatos praticamente fechados. Nessa avaliação (24/11/1999), a umidade do solo (Figura 4) correspondia ao ponto de murcha permanente ( $\psi=-1,5 \mathrm{MPa})$, em todas as camadas do tratamento leguminosa, de acordo com Fidalski (2004) (Figura 1). Esses valores foram superiores ao comprometimento da taxa de fotossíntese, condutância estomática e potencial da água da folha, observada por Chartzoulakis et al. (1999) na Grécia, com a reposição de água às laranjeiras por meio da irrigação para $\psi<-1,5 \mathrm{MPa}$.

As precipitações ocorridas em agosto, setembro e outubro de 2002 (Figura 2) foram insuficientes para atender à exigência hídrica das laranjeiras, embora a taxa de fotossíntese na manhã de 11/10/2002 não caracterizasse essa deficiência (Figura 3 e Tabela 1). No período da tarde, verificou-se redução acentuada da taxa de fotossíntese e da condutância estomática, em virtude do aumento do potencial da água das plantas, de -2,02 para -2,36 MPa (Tabela 1). Na manhã desse dia, quando as avaliações foram iniciadas, a temperatura do ar estava em $27^{\circ} \mathrm{C}$, e atingiu, à tarde, $41^{\circ} \mathrm{C}$ na câmara estomática, o que resultou em alto deficit de pressão de vapor, uma vez que o potencial da água das plantas não foi reduzido proporcionalmente à diminuição de umidade do solo (Figura 5).

O tratamento leguminosa apresentou, estatisticamente, menor umidade do solo na projeção da copa das plantas a 0,1-0,2 $\mathrm{m}$ de profundidade, correspondente ao horizonte A (textura arenosa; $80 \mathrm{~g} \mathrm{~kg}^{-1}$ de argila), não diferindo estatisticamente dos tratamentos gramínea e leguminosa no horizonte Bt (textura média; $180 \mathrm{~g} \mathrm{~kg}^{-1}$ ) a 0,25-0,40 m de profundidade (Figura 4), resultados semelhantes aos obtidos por Perin et al. (2000), com a mesma espécie de leguminosa, em um Argissolo.

A transição da umidade de solo entre horizontes A e Bt delimita a maior concentração do sistema radicular no perfil do solo, considerando o estudo de Neves et al. (1998) para o porta-enxerto limoeiro 'Cravo'. A menor 

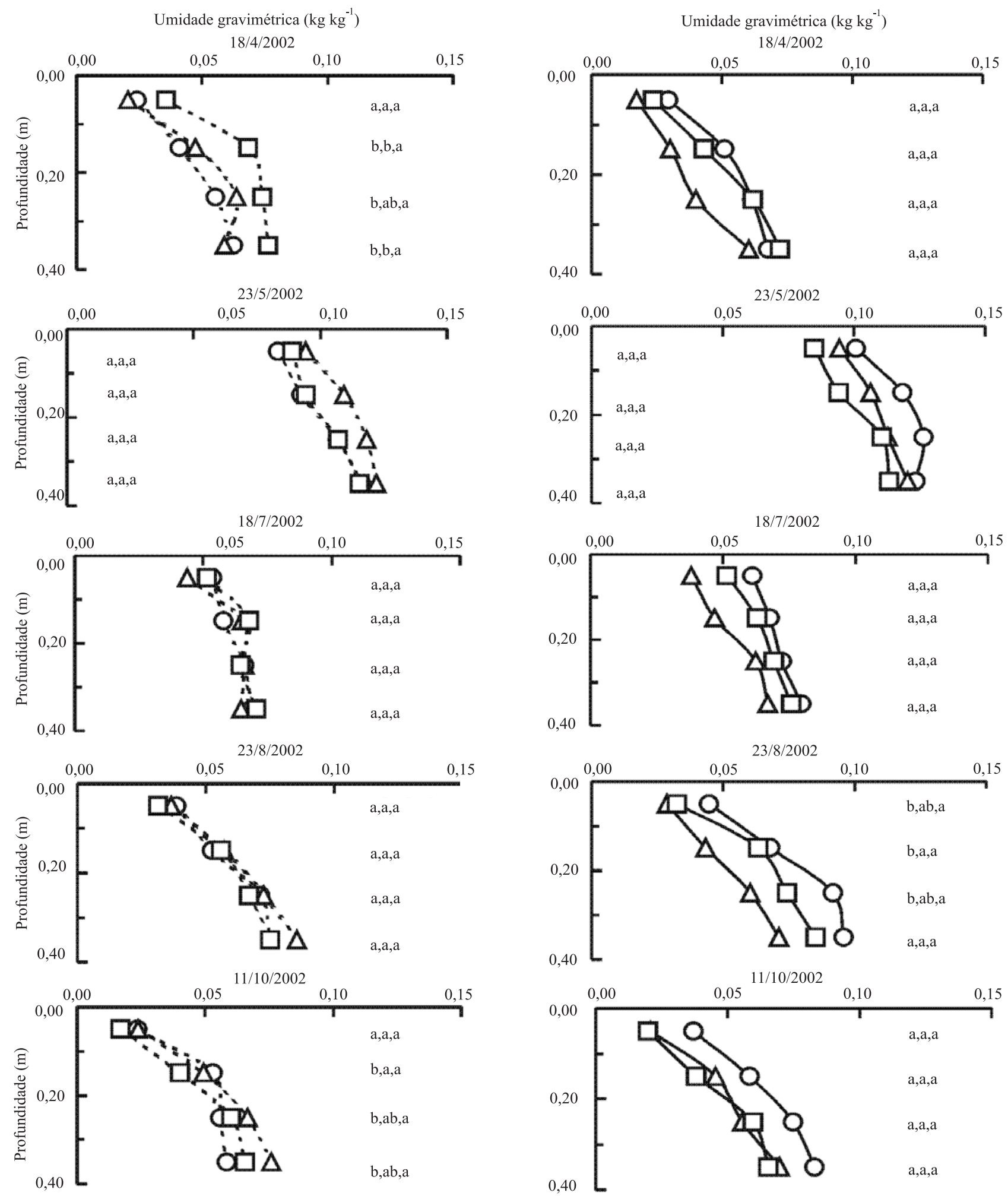

Figura 5. Umidade gravimétrica do solo na projeção da copa das plantas (---) e na entrelinha (-) do pomar de laranjeira 'Pêra', em 2002, nos tratamentos gramínea $(\bigcirc)$, leguminosa $(\square)$ e testemunha $(\triangle)$. Médias seguidas da mesma letra, dentro da mesma camada de solo, não diferem entre si pelo teste Tukey a 5\% de probabilidade. 
umidade na superfície do solo, observada no tratamento leguminosa, poderia estar associada aos efeitos do maior impedimento mecânico constatado nesse tratamento por Fidalski (2004), que pode controlar a abertura e o fechamento dos estômatos das plantas, segundo as indicações de pesquisa de Chartzoulakis et al. (1999) e Machado et al. (1999).

A produção de frutos de laranjeira 'Pêra' não foi influenciada pelos tratamentos de manejo de solo nas entrelinhas em 2000, 2001, 2002 e 2003 (Tabela 2). Isto significa que o estresse hídrico caracterizado em 24/11/1999, no tratamento leguminosa, não comprometeu estatisticamente a produção de frutos, em comparação à gramínea e à testemunha, na primeira colheita de 2000, e tampouco nas colheitas subseqüentes (Tabela 2). Os resultados da produção de frutos dão suporte à recomendação de se manter a vegetação permanente com gramínea nas entrelinhas de laranjeira, de acordo com Auler et al. (2004).

A fase de pré e pós-florescimento (agosto-outubro) correspondeu ao estádio fenológico e hídrico mais crítico para os citros no noroeste do Paraná, em consonância com Calheiros et al. (1992). Neste período, constatou-se, nas entrelinhas, maior umidade do solo no tratamento gramínea, comparado aos tratamentos leguminosa e testemunha (Figuras 4 e 5), confirmados pelas curvas de retenção de água, que indicaram que a umidade do solo no tratamento gramínea encontra-se no intervalo de água disponível, entre $\psi=-0,008 \mathrm{MPa}$ e $\psi=-1,5 \mathrm{MPa}$ (Figura 1).

Estresse hídrico com maior severidade ocorreu quando as precipitações mensais foram inferiores a $68 \mathrm{~mm}$, entre agosto e novembro de 1999 (Figura 2), valores inferiores aos índices pluviais médios da região (Iapar, 2000). Verificou-se o pleno metabolismo das laranjeiras em 5/4/2000 e 23/5/2002, por causa das temperaturas menores (Iapar, 2000) (Figura 3), sendo mais elevada a taxa de fotossíntese em 23/5/2002 (11,01 $\left.\mu \mathrm{mol} \mathrm{CO}_{2} \mathrm{~m}^{-2} \mathrm{~s}^{-1}\right)$, em virtude da maior umidade do solo (Figura 5), que se encontrava próxima à capacidade de campo, no potencial mátrico de -0,008 MPa, de acordo com Fidalski (2004) (Figura 1).

Tabela 2. Produção média de frutos $\left(\mathrm{kg}\right.$ planta $\left.^{-1}\right)$ de laranjeira 'Pêra', em razão da vegetação permanente nas entrelinhas, na primeira (I) e segunda (II) colheita, em diferentes anos(1).

\begin{tabular}{|c|c|c|c|c|c|c|}
\hline \multirow[t]{2}{*}{ Tratamento } & \multicolumn{3}{|c|}{2000} & \multirow[t]{2}{*}{2001} & \multirow[t]{2}{*}{2002} & \multirow[t]{2}{*}{2003} \\
\hline & I & II & Total & & & \\
\hline Gramínea & $90 a$ & $80 a$ & $170 a$ & $48 \mathrm{a}$ & $164 a$ & $116 a$ \\
\hline Leguminosa & $97 \mathrm{a}$ & $85 \mathrm{a}$ & $182 \mathrm{a}$ & $34 a$ & $185 \mathrm{a}$ & $154 \mathrm{a}$ \\
\hline Testemunha & $90 \mathrm{a}$ & $99 a$ & $189 a$ & $47 \mathrm{a}$ & $158 \mathrm{a}$ & $120 \mathrm{a}$ \\
\hline Média & 92 & 88 & 180 & 43 & 169 & 130 \\
\hline CV (\%) & 30 & 19 & 16 & 47 & 22 & 21 \\
\hline
\end{tabular}

${ }^{(1)}$ Médias seguidas da mesma letra, na coluna, no mesmo ano e colheita, não diferem entre si pelo teste Tukey a 5\% de probabilidade.
Os resultados deste trabalho contrariam informações de que o tratamento gramínea comprometeria as relações hídricas e fisiológicas das laranjeiras (Neves \& Dechen, 2001); indicam, no entanto, que o tratamento leguminosa exerce competição muito maior pela água do solo, tendo como referência o tratamento testemunha com a manutenção de menor taxa de cobertura do solo. A constatação das melhores relações hídricas entre o tratamento gramínea e das laranjeiras foi descrita por Fidalski (2004), que mostrou as melhores condições físicas e hídricas para o desenvolvimento das plantas, reforçada neste trabalho pela melhor eficiência nas relações hídricas entre os sistemas radiculares da gramínea e da laranjeira, assegurada pela maior disponibilidade de água no horizonte $\mathrm{Bt}$.

A adaptação da gramínea Paspalum notatum, na região focalizada, é descrita por Auler et al. (2004). Tratase de uma das espécies de gramínea indicada por Butler (1986) para o manejo, nas entrelinhas, de pomares de frutas decíduas em clima temperado. Este manejo de solo, baseado na manutenção de gramínea controlada por meio de roçadas mecânicas, sem o revolvimento do solo e sem a utilização de herbicida, tem apresentado resultados de qualidade do solo em outras espécies de gramíneas, em pomares de macieira e videira (Draghi et al., 2005; Ferrero et al., 2005). Outro aspecto técnico, que corrobora a manutenção da vegetação permanente sem revolvimento do solo nas entrelinhas dos pomares de laranjeiras, é a eficiência da calagem superficial em solo e cultura similares à deste trabalho, descrita por Fidalski \& Tormena (2005). Portanto, a manutenção da gramínea $P$. notatum nas entrelinhas de laranjeira 'Pêra', em solos que apresentam horizonte Bt, constitui-se um dos agroecossistemas citrícolas mais apropriados às condições edafoclimáticas da formação Caiuá, no noroeste do Paraná.

\section{Conclusões}

1. A manutenção da cobertura permanente com a leguminosa Arachis pintoi, nas entrelinhas do pomar, promove a competição pela água do solo com laranjeiras 'Pêra'.

2. O cultivo de laranjeiras intercaladas com a gramínea Paspalum notatum, em solo com horizonte Bt, proporciona as melhores relações hídricas e metabólicas às laranjeiras.

3. A produção de frutos de laranjeira 'Pêra' não é comprometida pela manutenção da cobertura vegetal permanente nas entrelinhas do pomar com a gramínea Paspalum notatum e com a leguminosa Arachis pintoi, em relação à testemunha com baixa cobertura vegetal. 


\section{Agradecimentos}

À Fundação Araucária do Estado do Paraná, pelo apoio financeiro ao projeto Manejo do solo e caracterização das relações hídricas em plantas de citros na região do Arenito Caiuá, noroeste do Estado do Paraná.

\section{Referências}

AULER, P.A.M.; FIDALSKI, J.; PAVAN, M.A.; GOMES, J.C.; JACOMINO, A.P. Sistema de preparo do solo, calagem e portaenxertos para a produção de laranja Valência na região noroeste do Paraná. In: CONGRESSO BRASILEIRO DE FRUTICULTURA, 18., 2004, Florianópolis. Anais. Florianópolis: SBF, 2004. 1 CD-ROM.

BUTLER, J.D. Grass interplanting in horticulture cropping systems. HortScience, v.21, p.394-397, 1986.

CALHEIROS, R.O.; OLIVEIRA, D.; CARAMORI, P.H.; GROSSI, M.E.D. Viabilidade técnica da irrigação em citros no norte e noroeste do Paraná. Pesquisa Agropecuária Brasileira, v.27, p.963-973, 1992.

CHARTZOULAKIS, K.; MICHELAKIS, N.; STEFANOUDAKI, E. Water use, growth, yield and fruit quality of 'Bonanza' oranges under different soil water regimes. Advances in Horticultural Science, v.13, p.6-11, 1999.

DANE, J.H.; TOPP, C. Methods of soil analysis: physical methods. Madison: Soil Science Society of America, 2002. v.4, 1692p

DRAGHI, L.; JORAJURÍA, D.; CERRISOLA, C.; MÁRQUEZ DELGADO, L. Resistência específica do solo de um pomar frutícola relacionada ao manejo entrelinhas e intensidade de tráfego. Engenharia Agrícola, v.25, p.385-394, 2005.

ESPINDOLA, J.A.A.; ALMEIDA, D.L. de; GUERRA, J.G.M.; SILVA, E.M.R. da; SOUZA, F.A. de. Influência da adubação verde na colonização micorrízica e na produção da batata-doce. Pesquisa Agropecuária Brasileira, v.33, p.339-347, 1998.

FERRERO, A.; USOWICZ, B.; LIPIEC, J. Effects of tractor traffic on spatial variability of soil strength and water content in grass covered and cultivated sloping vineyard. Soil and Tillage Research, v.84, p.127-138, 2005.

FIDALSKI, J. Propriedades físico-hídricas de um Argissolo Vermelho distrófico latossólico em diferentes sistemas de manejo das entrelinhas de citros. 2004. 62p. Dissertação (Mestrado) - Universidade Estadual de Maringá, Maringá.

FIDALSKI, J.; TORMENA, C.A. Dinâmica da calagem superficial em um Latossolo Vermelho distrófico. Revista Brasileira de Ciência do Solo, v.29, p.235-247, 2005.
IAPAR. Cartas climáticas do Paraná. Versão 1.0. Londrina, 2000. 1 CD-ROM.

LIPECKI, J.; BERBEC, S. Soil management in perennial crops: orchards and hop gardens. Soil and Tillage Research, v.43, p.169184, 1997.

MACHADO, E.C.; MEDINA, C.L.; GOMES, M.M.A. Teor de água no substrato de crescimento e fotossíntese em laranjeira 'Valência'. Bragantia, v.58, p.217-226, 1999.

MACHADO, E.C.; MEDINA, C.L.; GOMES, M.M.A.; HABERMANN, G. Variação da fotossíntese, condutância estomática e potencial da água na folha de laranjeira 'Valência'. Scientia Agricola, v.59, p.53-58, 2002.

MEDINA, C.L.; MACHADO, E.C.; GOMES, M.M.A. Condutância estomática, transpiração e fotossíntese em laranjeira 'Valência' sob deficiência hídrica. Revista Brasileira de Fisiologia Vegetal, v.11, p.29-34, 1999.

NEVES, C.S.V.J.; DECHEN, A.R. Sistemas de manejo de solo em pomar de tangerina 'Ponkan' sobre limão 'Cravo' em Latossolo Roxo. Laranja, v.22, p.167-184, 2001.

NEVES, C.S.V.J.; DECHEN, A.R.; FELLER, C.; SAAB, O.J.G.; PIEDADE, S.M.S. Efeito do manejo do solo no sistema radicular de tangerineira 'Poncã' enxertada sobre limoeiro 'Cravo' em Latossolo Roxo. Revista Brasileira de Fruticultura, v.20, p.246-253, 1998.

PERIN, A.; GUERRA, J.G.M.; TEIXEIRA, M.G. Efeito da morfologia radicular de leguminosas herbáceas perenes na umidade de um argissolo. Seropédica: Embrapa Agrobiologia, 2000. 8p. (Embrapa Agrobiologia. Comunicado técnico, 44).

SANTINONI, L.A.; SILVA, N.R. Crecimiento, producción y maduración del mandarino común bajo diferentes prácticas de manejo de suelo. Horticultura Argentina, v.14, p.5-11, 1995.

SAS INSTITUTE. SAS/STAT user's guide. Version 8.2. Cary, NC, 2001. 943p.

SCHOLANDER, P.F.; HAMMEL, H.T.; BRADSTREET, E.D.; HEMNINGSEN, E.A. Sap pressure in vascular plants. Science, v.148, p.339-346, 1965.

SOUZA, L.D.; SOUZA, L.S.; LEDO, C.A.S. Disponibilidade de água em pomar de citros submetido a poda e subsolagem em Latossolo Amarelo dos Tabuleiros Costeiros. Revista Brasileira de Fruticultura, v.26, p.69-73, 2004.

SYVERTSEN, J.P. Physiological determinants of citrus tree growth and development. In: SIMPÓSIO INTERNACIONAL DE FRUTICULTURA, 1., 1999, Botucatu. Anais. Botucatu: Fapesp, 1999. p.123-160.

VAN GENUCHTEN, M.T. A closed-form equation for predicting the hydraulic conductivity of unsaturated soils. Soil Science Society of America Journal, v.44, p.892-898, 1980. 